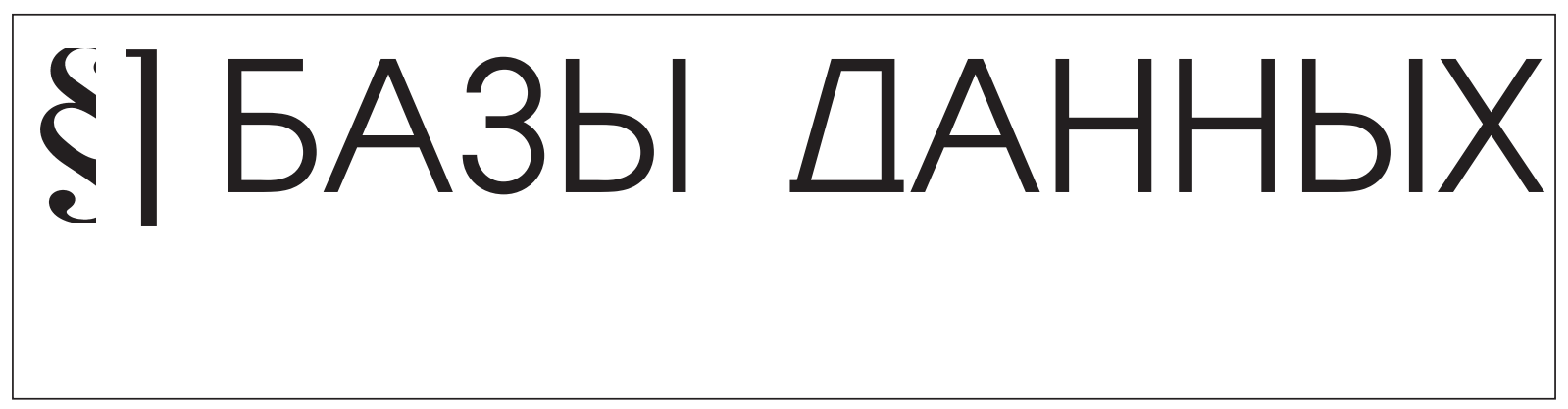

Мартышенко С.Н., Мартышенко Н.C.

\title{
КОМПЬЮТЕРНАЯ ТЕХНОЛОГИЯ ВЫЯВЛЕНИЯ И ОЦЕНКИ ПРИОРИТЕТОВ РЕШЕНИЯ СОЦИАЛЬНО-ЭКОНОМИЧЕСКИХ ПРОБЛЕМ РЕГИОНА (НА ПРИМЕРЕ ПРИМОРСКОГО КРАЯ)
}

\begin{abstract}
Аннотация: Предметом исследования являются компьютерные технологии обработки качественной информации. Для обработки данных используется когнитивный подход. Информационной базой создания когнитивных моделей выработки решений социальноэкономических проблем региона могут служить мнения, сформированные в результате обсуждения проблем в экспертных группах, при опросах населения региона, на инновационных семинарах. Когнитивное моделирование нашло применение при разработке управленческих решений в экономических, сочиологических, экологических и других слабоструктурированных системах. Особое внимание в статье уделяется пониманию социально-экономических проблем и явлений. Понимание проблемы является обязательным условием нахождения приемлемыхрешений. Методобработки качественной информации основан на применении операций типизации. Для повышения эффективности работы компьютерной технологии в нее включены элементы интеллектуальной системы. Разработанная компьютерная технология позволяет обрабатывать большие массивы неструктурированной информации, полученной в ходе мониторинга социально-экономических процессов. Достоинством технологии является ее простота использования и доступность широкому кругу пользователей, использующих в своей работе компьютерную среду EXCEL. Знания, накопленные в прочессе обработки открытых вопросов одним исследователем, легко можно передать другим исследователям в виде файла, что может существенно облегчить их работу.
\end{abstract}

Ключевые слова: компьютерная технология, когнитивная модель, качественные данные, типологизация, анкетный опрос, базы знаний, экспертная система, анализ данных, структурный анализ, сочиально-экономические прочессы 
Abstract: The object of the research is a computer technology of processing qualitative information. The authors used cognitive the approach for data processing. As information base for building cognitive models of finding the solutions of regional social and economic problems the authors use the opinions gained as a result of discussion of problems in expert groups, at interrogations of the population of region, at innovative seminars. Cognitive modeling is applied in finding administrative solutions in economic, sociological, ecological and others semistructured systems. The authors give special attention to understanding of social and economic problems and phenomena. The understanding of a problem is a prerequisite of a finding of comprehensible decisions. The method of processing of the qualitative information is based on typification. To increase an overall performance of computer technology the authors included elements of intellectual system in it. The developed computer technology allows processing big amounts of not structured information received during monitoring of social and economic processes. An advantage of the technology is in simplicity of use. It can be used by a wide range of the users familiar with the EXCEL environment. The knowledge formed in the processing of open questions by one researcher can be easily shared with other researchers in the form of a file that can essentially facilitate their work.

Keywords: structural analysis, data analysis, expert system, knowledge bases, questionnaire, typologization, qualitative data, cognitive model, computer technology, social and economic processes

\section{Введение}

В последние годы наблюдается возрастание интереса научного сообщества к развитию методов принятия решений и управления, основанных на принципах когнитивного подхода. Когнитивный подход основан на анализе и логическом обосновании процессов восприятия, мышления, познания, объяснения и понимания систем управления различной природы. Когнитивное моделирование нашло применение при разработке управленческих решений в экономических, социологических, экологических и других плохоформализуемых слабоструктурированных системах. Когнитивный подход используется в решении проблем понимания естественного языка, компьютерного перевода, теории искусственного интеллекта, компьютеризации всех сфер общественной деятельности $[1,2,3]$.

В реальных управленческих ситуациях очень часто возникает задача, которая состоит не в том, чтобы сделать выбор между альтернативными решениями с целью оптимизации, а в том, чтобы проанализировать ситуацию для выявления реальных проблем и определения причин их появления. Понимание проблемы - обязательное предварительное условие нахождения приемлемого решения [4].

Информационной базой создания когнитивных моделей выработки решений социально-экономических проблем региона могут служить мнения, сформированные в результате обсуждения проблем в экспертных группах, на инновационных семинарах, при опросах населения региона. 
При разработке когнитивных моделей социальных-экономических систем часто приходится сталкиваться с необходимостью обработки качественных данных ответов респондентов, получаемых с использованием открытых вопросов в анкетах. Преимуществом открытых вопросов является то, что с их помощью можно получить весь спектр мнений респондентов по исследуемой теме. При открытой форме вопроса исследователь не навязывает респонденту свои варианты ответов. Открытый вопрос вынуждает респондента задуматься над содержанием вопроса, что исключает возможность автоматического (недобросовестного) заполнения анкеты. Поэтому достоверность результатов исследований, основанных на использовании качественных ответов гораздо выше, чем при выборе из списка вариантов ответов, предложенных составителями анкеты. Однако при обработке качественных данных возникают большие трудности технического характера. Кроме того, для получения результатов, адекватно описывающих ситуацию, необходимы выборки гораздо большего объема, чем при использовании других типов вопросов.

Теоретические основы анализа качественной информации представлены в работах российских социологов Г.Г. Татаровой и Ю.Н. Толстовой [5, 6]. В основе обработки качественных данных лежит процедура типологизации.

Типологизация (анг. typologization) - процедура систематизации знаний об изучаемых феноменах либо для введения (задания) типов, либо для поиска знаний о типах [5].

Известные социологи Н. Филдинг и Р. Ли, специализирующиеся в области разработки инструментальных средств анализа качественных данных, предложили использовать специальный термин «компьютерный ассистируемый анализ качественных данных» (Computer Assisted Qualitative Data AnalysiS, CAQDAS) [7]. Ассистируемый анализ представлен множеством компьютерных пакетов, в том числе: Atlas.ti, MAXQDA, NVivo, xSight, Qualrus, Ethnograph и др.

В настоящей работе предлагается собственная компьютерная технология структуризации качественной информации, полученной от респондентов в анкетных опросах населения и их количественного анализа.

\section{Основные элементы компьютерной технологии структуризации качественных данных, полученных в ходе анкетных опросов}

В саму природу нечисловой информации заложена возможность использования для ее обобщения и структуризации типологического анализа. «При всей уникальности действующего индивида большая часть его индивидуальных смыслов типична, т. е. обладает общностью с другими людьми» [8].

Для автоматизации обработки качественных данных открытых вопросов нами была разработана специальная компьютерная технология. Предложенная технология предполагает, что ответ респондента на открытый вопрос анкеты может включать несколько вариантов ответов. Например, при ответе на вопрос: «Назовите несколько социальноэкономических, политических и других проблем, которые более всего беспокоят Вас и окружающих людей», один из респондентов указал следующие проблемы (варианты 
ответов): высокий уровень бедности, постоянное повышение цен, высокие цены на коммунальные услуги. В реальных ответах может содержаться некоторая избыточная информация в виде пояснений или эмоциональной составляющей.

Для того чтобы качественные данные таких ответов могли быть пригодны для количественного анализа, все высказывания требуется привести к некоторому структурированному виду. На предварительном этапе первичные данные, содержащие несколько вариантов ответов, должны быть разделены с помощью какого-набуть знака разделения. В текстовом представлении информации естественным разделителем вариантов ответа может служить знак точки («.»). В реальной ситуации в одном предложении респондент может выразить свой ответ так, что он по смыслу содержит в себе несколько более простых ответов.

Для формализованного представления данных анкетных опросов удобно использовать понятие таблицы «объект-свойство» [9]. «Объектом» в случае анкетных данных является респондент, которые отвечает на вопросы анкеты. «Свойство» - это некоторое значение (числовое или текстовое), которое содержится в ответе респондента на определенный вопрос. В классической статистике для определения понятия «свойство» используется термин «признак».

В компьютерном представлении, например в таблице EXCEL, ответы на один вопрос анкеты могут быть представлены в одном или нескольких столбцах таблицы данных. Количество столбцов зависит как от формы самого вопроса, так и от метода обработки данных, который предполагается использовать для обработки данных ответа на вопрос.

Для компьютерного представления ответов на открытый вопрос, допускающий несколько вариантов ответов, в разработанной технологии, предполагается использование одного столбца таблицы данных. Для идентификации вариантов ответов используется оговоренный знак разделения ответов. Для такого признака мы ввели специальный термин - «составной признак». Для обработки таких признаков потребовалась разработка специальных компьютерных средств обработки данных.

Альтернативным способом представления данных такого признака могло бы быть представление различных вариантов ответов в различных столбцах таблицы данных. Но такое представление признаков оказалось крайне неудобным с точки зрения обработки (анализа) данных, из-за возникающих неопределенностей. Во-первых, количество вариантов ответов заранее не известно. Во-вторых, при обработке данных одного варианта ответа может оказаться, что он на самом деле распадается на несколько более простых вариантов. И в-третьих, формулировка вопроса вообще может не требовать от респондента указывать варианты ответов, а просто выразить свое мнение несколькими фразами. В последнем случае выделение вариантов вообще является компетенцией исследователя.

Для того чтобы качественные данные составного признака могли бы быть подвергнуты количественному анализу, необходимо произвести преобразование данных от неструктурированного вида к структурированному. Рассмотрим основные элементы компьютерной технологии структуризации данных составного признака (рис. 1).

Компьютерная технология реализована в виде приложения к EXCEL. Она основана 
на использовании операции типизации. Суть операции типизации состоит в замене исходного высказывания (варианта ответа в форме текста) на близкое или сходное по значению, или некоторое обобщающее высказывание (в форме текста).

Для выполнения операции типизации по данным составного признака формируется некоторая вспомогательная таблица - «список значений признака». В эту таблицу включаются все уникальные ответы по всем вариантам ответов. Для учета повторяющихся ответов в таблице «список значений признака» введен столбец кратности (частоты) ответа. Все преобразования, связанные с типизацией, выполняются с данными таблицы «список значений признака», которые затем возвращаются в таблицу исходных данных. Такой подход позволяет существенно сократить объем таблицы данных, подвергающихся корректировке. С другой стороны, такой подход исключает ошибки при корректировке одинаковых ответов. При корректировке данных таблицы «список значений признака» широко используются фильтры EXCEL.

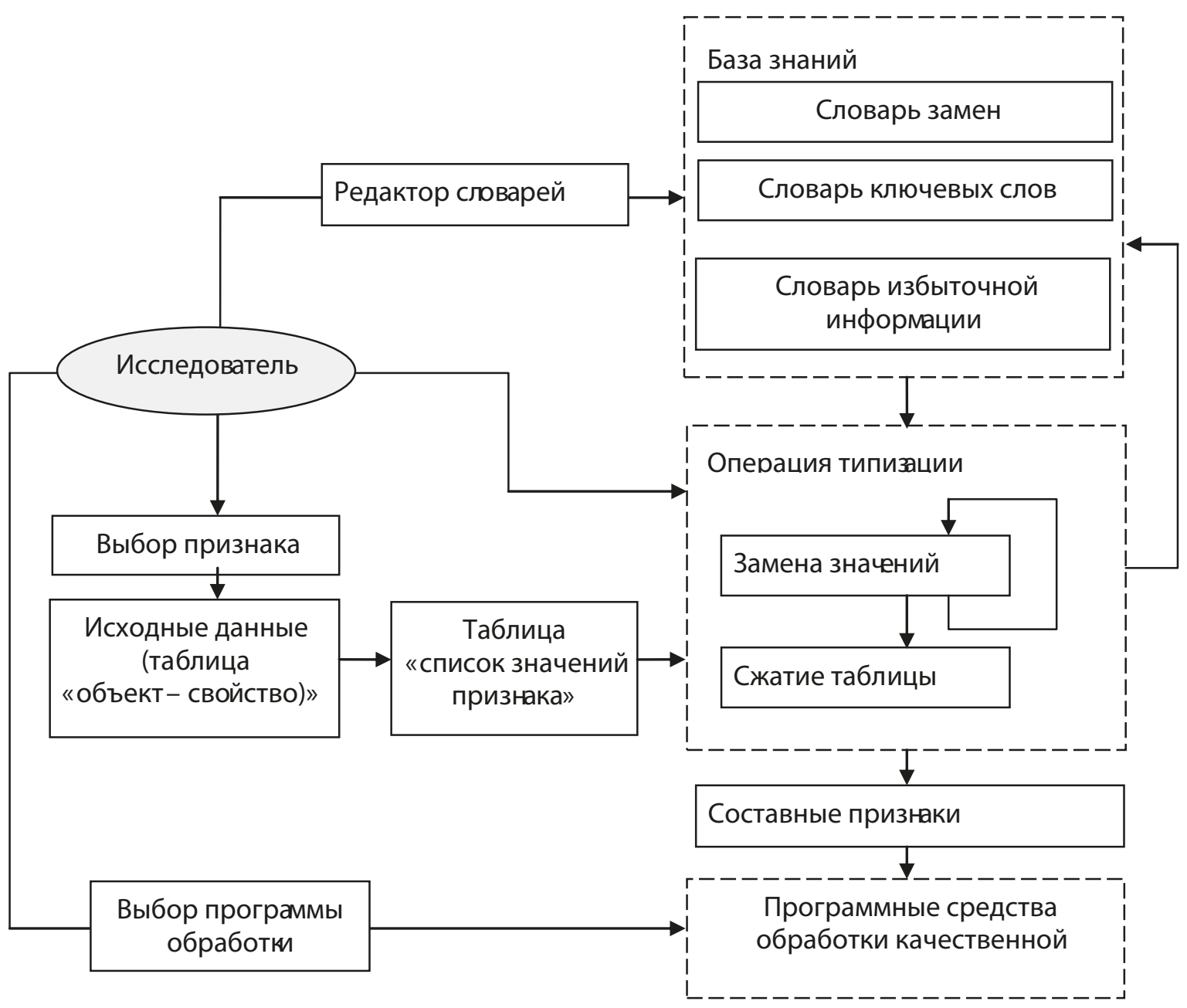

Рис. 1. Компьютерная технология обработки неструктурированных данных 
Работа по структурированию данных качественных ответов производится в несколько этапов.

\section{Первый этап}

На этом этапе в начале обрабатываются простые ситуации. Например, отыскиваются ответы отличающиеся написанием одного слова или различным порядком слов. Среди сходных высказываний выбирается наиболее удачная (или грамотная) форма написания ответа, затем такой ответ копируется в ячейки таблицы «список значений признака» со сходными ответами. Выполняя замену какого-то уникального ответа на уже существующее из списка значений, мы тем самым сокращаем количество строк таблицы «список значений признака». После выполнения серии замен целесообразно выполнять операцию «сжатия», которая заключается в пересчете значений таблицы «список значений признака». Постепенно таблица «список значений признака» сокращается и становится более наглядной. При простых заменах не происходит искажения смысла исходной информации.

После того как простые ситуации обработаны, приступают к обработке более сложных случаев. В таблице «список значений признака» отыскивается группа редко встречающихся, но касающихся одной темы ответов. Для этой группы ответов исследователь подбирает в таблице «список значений признака» некоторый обобщающий ответ, и если такого не находит, то сам формулирует свой обобщающий ответ, отражающий общий смысл или тему группы ответов.

Например, при ответе на вопрос «Назовите несколько социально-экономических, политических и других проблем, которые более всего беспокоят Вас и окружающих людей», неоднократно встречался ответ «благоустройство города». Наряду с другими ответами различные респонденты давали еще такие ответы: «благоустройство дворов», «благоустройство придомовых территорий», «благоустройство домов», «качество тротуаров», «лед на дорогах» и т.п.. Но эти ответы встречались достаточно редко (менее 0,05\%), поэтому мы заменили их на обобщающее высказывание - «благоустройство города», которое нашли в таблице «список значений признака». В принципе, смысл высказываний сохранился. И все-таки, чтобы не потерять информацию, особенно при повторном проведении опросов, сходные высказывания заменяются на обобщающие, но с уточнением. Уточнение или нюанс указывается в скобках. Например, в рассмотренном выше случае, оригинальные значения были заменнены на:

- благоустройство города (благоустройство дворов);

- благоустройство города (благоустройство придомовых территорий);

- благоустройство города (благоустройство домов);

- благоустройство города (качество тротуаров);

- благоустройство города (лед на дорогах).

При обработке данных ответов на вопрос по проблемам, которые беспокоят жителей, к категории «благоустройство города» было отнесено всего 69 близких по смыслу 
ответов, а вся группа ответов объединила 118 ответов. То есть отдельные ответы тоже встречались неоднократно.

Если исходная таблица «список значений признака» может содержать до нескольких тысяч значений, то после обработки (типизации) данных такая таблица обычно содержит (с учетом значений с уточнениями) до трехсот-четырехсот значений. Созданием такой таблицы заканчивается первый этап типизации (первый уровень). Даже при автоматизации процесса, работа по систематизации ответов респондентов занимает у исследователя достаточно много времени, требует большой внимательности и наличия определенных навыков (опыта работы). И, конечно, эта работа не может быть выполнена за один сеанс работы. Поэтому при завершении сеанса, результаты сохраняются, и в следующем сеансе работа продолжается с того места, где она была приостановлена.

\section{Второй этап}

Полученный на первом этапе преобразованный признак содержит все еще слишком много значений, чтобы его можно было анализировать с помощью числовых методов. Поэтому этот признак подвергается дополнительной обработке (второй уровень типизации). На этом этапе просто исключаются уточнения, содержащиеся в скобках, и формируется еще один столбец таблицы «список значений признака», который мы называем подкласс. Этот столбец будет содержать уже от 30 до 50 уникальных значений.

\section{Третий этап}

Наличие 30-50 вариантов значенийпризнака - также большое количество для анализа измерений в номинальной шкале. Поэтому исследователь после формирования приемлемого списка действительно различных вариантов ответов, должен сгруппировать эти ответы, рассматривая их как некоторые характеристики непересекающихся классов, типов или тем в зависимости от содержательного смысла признака и постановки задачи, для которой производится типизация. Объединение более простых ответов в классы является третьим уровнем типизации. Для каждого класса исследователь сам формулирует название в зависимости от характера объединяемых высказываний.

На практике, результаты классификации у разных исследователей получаются очень похожими. Различия могут возникать из-за того, что некоторые высказывания действительно могут занимать промежуточное состояние и могут быть отнесены сразу к нескольким классам. А вот названия классов каждый исследователь может дать совершенно разные.

Таким образом, в результате обработки данных открытого вопроса будут получены (на выходе):

- $\quad$ три новых представления признака («свойства»), которые включаются в исходную таблицу данных и могут быть подвергнуты дальнейшей обработке для получения 
содержательных выводов;

- таблицу «список значений признака», которая может быть использована для обработки данных при повторении анкетного опроса или для выявления типизаций данных других опросов, которые предназначены для исследования данного процесса.

Отметим, что в результате типизации составных признаков будут сформированы также составные признаки. Для количественного анализа таких признаков были разработаны специальные инструментальные средства обработки данных [10, 11].

Обычно, анкетные опросы по исследованию социально-экономических процессов повторяются с некоторой периодичностью. В процессе мониторинга ситуации определяются тенденции изменения ситуации, оценивается эффективность управленческих решений. Поэтому, чтобы облегчить работу в будущем в процессе работы по типизации данных создается база знаний по исследуемой теме. Компьютерные технологии, позволяющие использовать базы знаний, относятся к классу экспертных систем. Главная отличительная особенность экспертной системы заключается в умении делать правильные предсказания. Производя всевозможные подсказки пользователю во время его работы, специальные программные средства позволяют существенно сократить время работы пользователя по структуризации данных. Подсказки пользователю осуществляются с помощью специальных словарей.

В разработанной технологии база знаний создается в форме трех словарей: «Словарь замен», «Словарь избыточной информации», «Словарь ключевых слов». Формирование словарей происходит в процессе работы пользователя над задачей типизации. Словари хранят опыт пользователя, приобретенный им в процессе решения задач типизации качественных признаков. Все словари хранятся в единой базе данных Access, которая подключается к файлу с данными в EXCEL. Рассмотрим структуру и функции используемых словарей.

«Словарь замен» формируется автоматически при выполнении пользователем замен одних текстовых ответов на другие. Словарь пополняется при работе пользователя с программой типизации. «Словарь замен» хранит все замены, выполненные пользователем. При повторении анкетного опроса приходится опять производить операцию типизации с новыми данными. Оказывается, что при повторном сборе информации ситуации, обработанные пользователем на предыдущих этапах, в подавляющем числе случаев повторяются. Подключив «Словарь замен», пользователь получит подсказки по заменам, которые производились ранее. И тогда пользователю останется только обработать ситуации, которые ранее не встречались. Сопровождение словаря практически не требует дополнительных затрат времени. При повторных опросах время на обработку качественных данных может сократиться на порядок.

Часто, при ответах на открытые вопросы анкет респонденты используют вводные слова, содержат обороты, содержащие эмоциональную составляющую. Поэтому, прежде чем обрабатывать такие данные, целесообразно, по возможности, очистить данные от избыточной информации, которая с точки зрения исследуемого процесса не несет 
смысловой нагрузки. Для этого используется «Словарь избыточной информации». В отличие от «Словаря замен», которые создаются для каждого качественного признака, этот словарь работает сразу со всеми качественными признаками, которые могут быть получены с использованием различных анкет. Словарь используется на первом этапе обработки качественной текстовой информации. С помощью этого словаря удаляются или корректируются высказывания, содержащие различную избыточную и несодержательную информацию. Например, с помощью словаря могут быть исключены такие словосочетания, как: «Я думаю, что», «По моему мнению», «Это, в свою очередь» и т. п. В этот словарь включаются и слова с типовыми обобщениями. Например, сокращения «о» или «о.» программа будет предлагать заменять на слово «остров». «Словарь избыточной информации» оказывается очень полезным при обработке длинных фраз и предложений. С помощью этого словаря удается существенно сократить таблицу «список значений признака» на первом этапе работы, тем самым снизить трудоемкость обработки данных. Программные средства, работающие со «Словарем избыточной информации», не производят автоматических замен или корректировок текстов, они выделяют цветом неинформативные фрагменты текста, а действия по изменению текста производит непосредственно сам исследователь. «Словарь избыточной информации» пополняется и редактируется самим исследователем по мере накопления опыта обработки качественной информации.

Некоторые вопросы анкет могут порождать ответы респондентов в виде нескольких сложных предложений (длинных фраз). В этом случае на первых этапах обработки данных «список значений признака» очень велик из-за того, что полное совпадение ответов встречается крайне редко. Для поиска сходных ответов в большом списке длинных фраз (ответов) удобно использовать фильтры EXCEL. Если в фильтрах установить некоторые ключевые слова для ответов с высокой частотой встречаемости, поле поиска сходных ответов сужается. Этот принцип заложен в основу процедуры поиска сходных ответов с помощью «словаря ключевых слов». Этот словарь имеет достаточно сложную структуру. Он состоит из четырех взаимосвязанных таблиц. При формировании «словаря ключевых слов» сочетаются функции работы исследователя с автоматическими функциями, выполняемыми компьютерной программой. То есть, для формирования словаря используется человеко-машинная процедура. В данной работе мы не будем вдаваться в подробности технической реализации «словаря ключевых слов». При подключении этого словаря специальная программа анализирует данные таблицы «список значений признака» и для необработанных ответов пытается подобрать похожий ответ среди ранее обработанных. В процессе работы исследователя происходит накопление информации (обучение словаря) и он со временем начинает работать все лучше и лучше.

\section{Анализ структуры данных ответов респондентов по социально-экономическим проблемам региона}

Возможности компьютерных программ обработки качественных данных продемон- 
стрируем на примере обработки данных вопроса по исследованию социально-экономических проблем региона (Приморского края). Вопрос по проблемам региона был использован в двух типах анкет. Опросы по этим анкетам производились в период с октября 2009 года по апрель 2014 года. Распределение количества анкет по годам приведено на рис 2. Всего за этот период было опрошено 6718 жителей Приморского края. Всего в ответах респондентов было указано 18885 проблем, которые беспокоят население края. Многие варианты ответов повторялись или были достаточно близки.

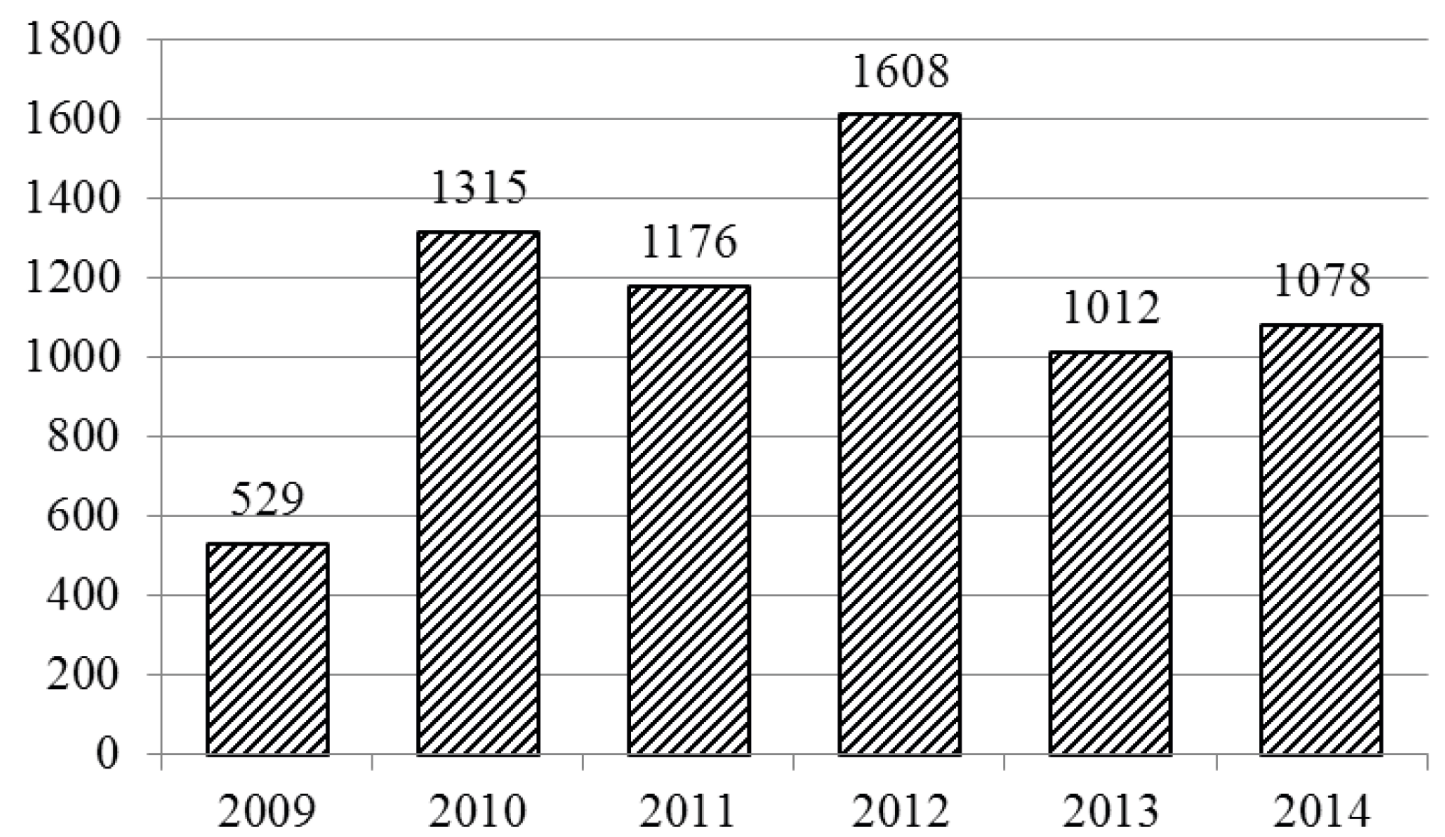

Рис. 2. Распределение опрошенных респондентов по годам

Обработка качественных данных производилась по мере сбора данных. В окончательном варианте таблица «список значений признака» содержит 5240 вариантов ответа. По всем вариантам ответов были сформированы 80 групп (подклассов) вариантов ответов, включающих очень близкие по смыслу ответы. Одна группа ответов содержит единичные ответы, которые не могли быть отнесены ни к одной группе. Количество ответов в этой группе составило всего 0,05\%. Из дальнейшего анализа такие ответы были исключены. Количество респондентов, которые отказались от ответа на данный вопрос, составило 0,2\%.

Выделенные группы ответов были объединены в 18 близких по тематике классов ответов. Сформированная в результате обработки первичных данных структура вариантов ответов населения Приморского края по проблемам, которые их больше всего беспокоят, представлена в табл.1. 


\begin{tabular}{|c|c|c|c|c|}
\hline № & Классы ответов & Группы (подклассы) ответов & $\begin{array}{c}\text { Частоты } \\
\text { внутри } \\
\text { групп }\end{array}$ & $\begin{array}{l}\text { Частоты } \\
\text { классов }\end{array}$ \\
\hline \multirow{10}{*}{1} & \multirow{10}{*}{ Ценовая политика } & высокие цены на жилье & 0,23 & \multirow{10}{*}{0,18} \\
\hline & & $\begin{array}{l}\text { высокие цены на коммунальные } \\
\text { услуги }\end{array}$ & 0,17 & \\
\hline & & высокие цены на продукты питания & 0,14 & \\
\hline & & высокие цены & 0,14 & \\
\hline & & высокие цены на бензин & 0,09 & \\
\hline & & постоянное повышение цен & 0,09 & \\
\hline & & высокий уровень инфляции & 0,06 & \\
\hline & & $\begin{array}{l}\text { ценовая политика в Приморском } \\
\text { крае }\end{array}$ & 0,05 & \\
\hline & & $\begin{array}{l}\text { высокая стоимость поездок в } \\
\text { другие регионы страны }\end{array}$ & 0,02 & \\
\hline & & высокие цены на услуги & 0,02 & \\
\hline \multirow{10}{*}{2} & \multirow{10}{*}{$\begin{array}{l}\text { Низкое качество } \\
\text { жизни }\end{array}$} & $\begin{array}{l}\text { плохое качество медицинского } \\
\text { обслуживания }\end{array}$ & 0,43 & \multirow{10}{*}{0,11} \\
\hline & & низкий уровень жизни населения & 0,19 & \\
\hline & & низкий уровень качества жизни & 0,11 & \\
\hline & & $\begin{array}{l}\text { высокие цены на медицинские } \\
\text { услуги }\end{array}$ & 0,09 & \\
\hline & & $\begin{array}{l}\text { низкое качество коммунальных } \\
\text { услуг }\end{array}$ & 0,07 & \\
\hline & & низкое качество продуктов питания & 0,05 & \\
\hline & & низкая продолжительность жизни & 0,03 & \\
\hline & & $\begin{array}{l}\text { распространение опасных } \\
\text { заболеваний }\end{array}$ & 0,02 & \\
\hline & & отдаленность от центра России & 0,02 & \\
\hline & & плохие условия труда & 0,01 & \\
\hline
\end{tabular}




\begin{tabular}{|c|c|c|c|c|}
\hline \multirow{10}{*}{3} & \multirow{10}{*}{$\begin{array}{l}\text { Забота о будущем } \\
\text { поколении }\end{array}$} & низкое качество образования & 0,26 & \multirow{10}{*}{0,10} \\
\hline & & высокая плата за образование & 0,18 & \\
\hline & & нехватка мест в детских садах & 0,10 & \\
\hline & & забота о подрастающем поколении & 0,09 & \\
\hline & & проблема наркомании & 0,09 & \\
\hline & & демографические проблемы & 0,08 & \\
\hline & & проблемы нравственности & 0,07 & \\
\hline & & низкая культура населения & 0,05 & \\
\hline & & $\begin{array}{l}\text { проблемы молодежи и } \\
\text { молодежная политика }\end{array}$ & 0,05 & \\
\hline & & проблема курения & 0,02 & \\
\hline \multirow{7}{*}{4} & \multirow{7}{*}{$\begin{array}{l}\text { Инфраструктура и } \\
\text { благоустройство }\end{array}$} & плохие автодороги & 0,46 & \multirow{7}{*}{0,09} \\
\hline & & проблемы на дорогах & 0,24 & \\
\hline & & $\begin{array}{l}\text { навести чистоту в городах и } \\
\text { населенных пунктах }\end{array}$ & 0,10 & \\
\hline & & $\begin{array}{l}\text { проблемы с общественным } \\
\text { транспортом }\end{array}$ & 0,08 & \\
\hline & & благоустройство города & 0,08 & \\
\hline & & неразвитая инфраструктура & 0,03 & \\
\hline & & градостроительство & 0,02 & \\
\hline 5 & $\begin{array}{l}\text { Низкая заработная } \\
\text { плата }\end{array}$ & низкая заработная плата & 1 & 0,06 \\
\hline \multirow{6}{*}{6} & \multirow{6}{*}{$\begin{array}{l}\text { Социальная } \\
\text { напряженность и } \\
\text { бедность }\end{array}$} & $\begin{array}{l}\text { национальный вопрос и проблема } \\
\text { иммиграции }\end{array}$ & 0,35 & \multirow{6}{*}{0,06} \\
\hline & & политическая нестабильность & 0,22 & \\
\hline & & рост потребления алкоголя & 0,17 & \\
\hline & & социальная напряженность & 0,13 & \\
\hline & & высокий уровень бедности & 0,11 & \\
\hline & & нарушение прав человека & 0,03 & \\
\hline
\end{tabular}




\begin{tabular}{|c|c|c|c|c|}
\hline \multirow{3}{*}{7} & \multirow{3}{*}{$\begin{array}{l}\text { Коррупция и } \\
\text { преступность в } \\
\text { органах власти }\end{array}$} & коррупция & 0,82 & \multirow{3}{*}{0,06} \\
\hline & & преступность в органах власти & 0,15 & \\
\hline & & $\begin{array}{l}\text { разграбление природных ресурсов } \\
\text { страны }\end{array}$ & 0,03 & \\
\hline \multirow{3}{*}{8} & \multirow{3}{*}{$\begin{array}{l}\text { Экологические } \\
\text { проблемы и } \\
\text { природоохрана }\end{array}$} & экологические проблемы & 0,94 & \multirow{3}{*}{0,06} \\
\hline & & природоохранные мероприятия & 0,03 & \\
\hline & & вырубка лесов & 0,02 & \\
\hline \multirow{3}{*}{9} & \multirow{3}{*}{$\begin{array}{l}\text { Трудоустройство и } \\
\text { занятость }\end{array}$} & высокий уровень безработицы & 0,48 & \multirow{3}{*}{0,05} \\
\hline & & проблемы с трудоустройством & 0,42 & \\
\hline & & $\begin{array}{l}\text { восстановление реального сектора } \\
\text { экономики }\end{array}$ & 0,11 & \\
\hline \multirow{3}{*}{10} & \multirow{3}{*}{$\begin{array}{l}\text { Низкая социальная } \\
\text { защищенность }\end{array}$} & низкая социальная защищенность & 0,56 & \multirow{3}{*}{0,05} \\
\hline & & низкие пенсии & 0,40 & \\
\hline & & $\begin{array}{l}\text { нарушение трудового } \\
\text { законодательства }\end{array}$ & 0,04 & \\
\hline \multirow{4}{*}{11} & \multirow{4}{*}{$\begin{array}{l}\text { Неудовлетворенность } \\
\text { работой властных } \\
\text { структур }\end{array}$} & недоверие к органам власти & 0,36 & \multirow{4}{*}{0,05} \\
\hline & & плохая работа администрации края & 0,23 & \\
\hline & & недоверие к правительству страны & 0,23 & \\
\hline & & безразличие власти к народу & 0,17 & \\
\hline \multirow{2}{*}{12} & \multirow{2}{*}{$\begin{array}{l}\text { Преступность и } \\
\text { личная безопасность }\end{array}$} & высокий уровень преступности & 0,70 & \multirow{2}{*}{0,05} \\
\hline & & личная безопасность & 0,30 & \\
\hline \multirow{3}{*}{13} & \multirow{3}{*}{$\begin{array}{l}\text { Нестабильность } \\
\text { экономической } \\
\text { ситуации }\end{array}$} & $\begin{array}{l}\text { нестабильность экономической } \\
\text { ситуации }\end{array}$ & 0,41 & \multirow{3}{*}{0,03} \\
\hline & & $\begin{array}{l}\text { нестабильность социально- } \\
\text { экономической обстановки }\end{array}$ & 0,32 & \\
\hline & & экономический кризис & 0,27 & \\
\hline
\end{tabular}




\begin{tabular}{|c|c|c|c|c|}
\hline \multirow{5}{*}{14} & \multirow{5}{*}{$\begin{array}{l}\text { Несовершенное } \\
\text { законодательство }\end{array}$} & высокие налоги & 0,37 & \multirow{5}{*}{0,02} \\
\hline & & несовершенное законодательство & 0,29 & \\
\hline & & высокие таможенные пошлины & 0,18 & \\
\hline & & $\begin{array}{l}\text { предпринимательство и малый } \\
\text { бизнес }\end{array}$ & 0,09 & \\
\hline & & $\begin{array}{l}\text { средства массовой информации и } \\
\text { реклама }\end{array}$ & 0,07 & \\
\hline \multirow{4}{*}{15} & \multirow{4}{*}{$\begin{array}{l}\text { Доступность отдыха и } \\
\text { развлечений }\end{array}$} & плохие условия для отдыха & 0,40 & \multirow{4}{*}{0,01} \\
\hline & & развитие туризма и спорта & 0,28 & \\
\hline & & доступность отдыха & 0,19 & \\
\hline & & досуг и развлечение & 0,12 & \\
\hline 16 & $\begin{array}{l}\text { Международная } \\
\text { обстановка }\end{array}$ & международная обстановка & 1 & 0,01 \\
\hline \multirow{2}{*}{17} & \multirow{2}{*}{$\begin{array}{l}\text { Низкое качество } \\
\text { товаров и услуг }\end{array}$} & низкое качество товаров и услуг & 0,69 & \multirow{2}{*}{0,01} \\
\hline & & несоответствие цены качеству & 0,31 & \\
\hline \multirow{2}{*}{18} & \multirow{2}{*}{$\begin{array}{l}\text { Глобальные } \\
\text { катаклизмы и } \\
\text { катастрофы }\end{array}$} & природные катаклизмы & 0,65 & \multirow{2}{*}{0,003} \\
\hline & & угроза радиации & 0,35 & \\
\hline
\end{tabular}

Распределение групп ответов по классам выполняется исследователем и носит субъективный характер. Другие исследователи могли бы объединить в классы и другие группы ответов. В таблице 1 представлены два вида частотных рядов. Первый вид частотных рядов оценивает распределение групп ответов внутри классов, второй вид оценивает частоту классов ответов по всей выборке. Для расчета частотных рядов была разработана специальная компьютерная программа, которая позволяет рассчитывать частотные ряды для составных признаков. Частотный ряд классов ответов по проблемам, с которыми сталкиваются жители Приморского края, представлен на рис. 3.

Более полную информацию о проблемах дают частотные ряды по отдельным классам проблем. Так, например, в классе проблем «Ценовая политика» выделяется группа проблем, связанная с трудностями приобретения собственного жилья (23\%).

Распределение ответов респондентов в пределах одного класса ответов рассмотрим на примере такого важнейшего класса ответов, как «Забота о будущем поколении» (рис. 4).

Из рисунка следует, что в проблеме «Забота о будущем поколении» население больше всего волнует качество образования и высокая плата за обучение, которая не всегда 
доступна для семейного бюджета.

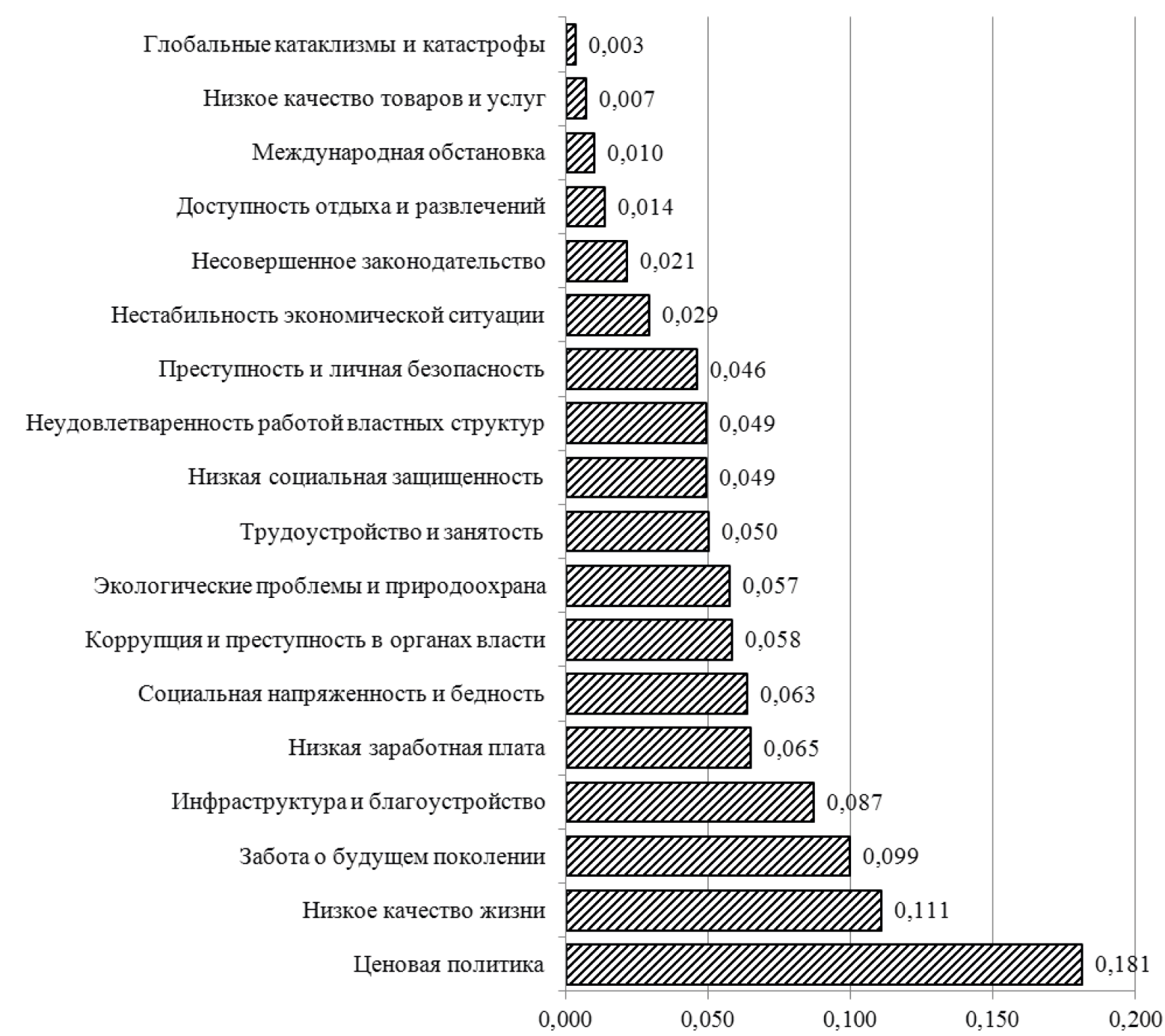

Рис. 3. Частотный ряд распределения классов проблем, которые беспокоят жителей Приморского края

В одну группу ответов могут быть объединены ответы, включающие различные характеристики группы. Например, такая группа, как «забота о подрастающем поколении» носит обобщающий характер. В нее, наряду с другими ответами, включены такие ответы: - $\quad$ забота о подрастающем поколении (будущее детей) - 59 ответов;

- $\quad$ забота о подрастающем поколении (детская беспризорность) 13 ответов;

- забота о подрастающем поколении (мало детских площадок) - 13 ответов;

- $\quad$ забота о подрастающем поколении (отсутствие парков для детей) - 7 ответов.

При анализе определенного класса ответов, при необходимости, можно просмотреть конкретные ответы респондентов в таблице «список значений признака». В этой таблице ответы одной группы вполне наглядны. В полной таблице данных при больших выборках 
такой анализ невозможен.

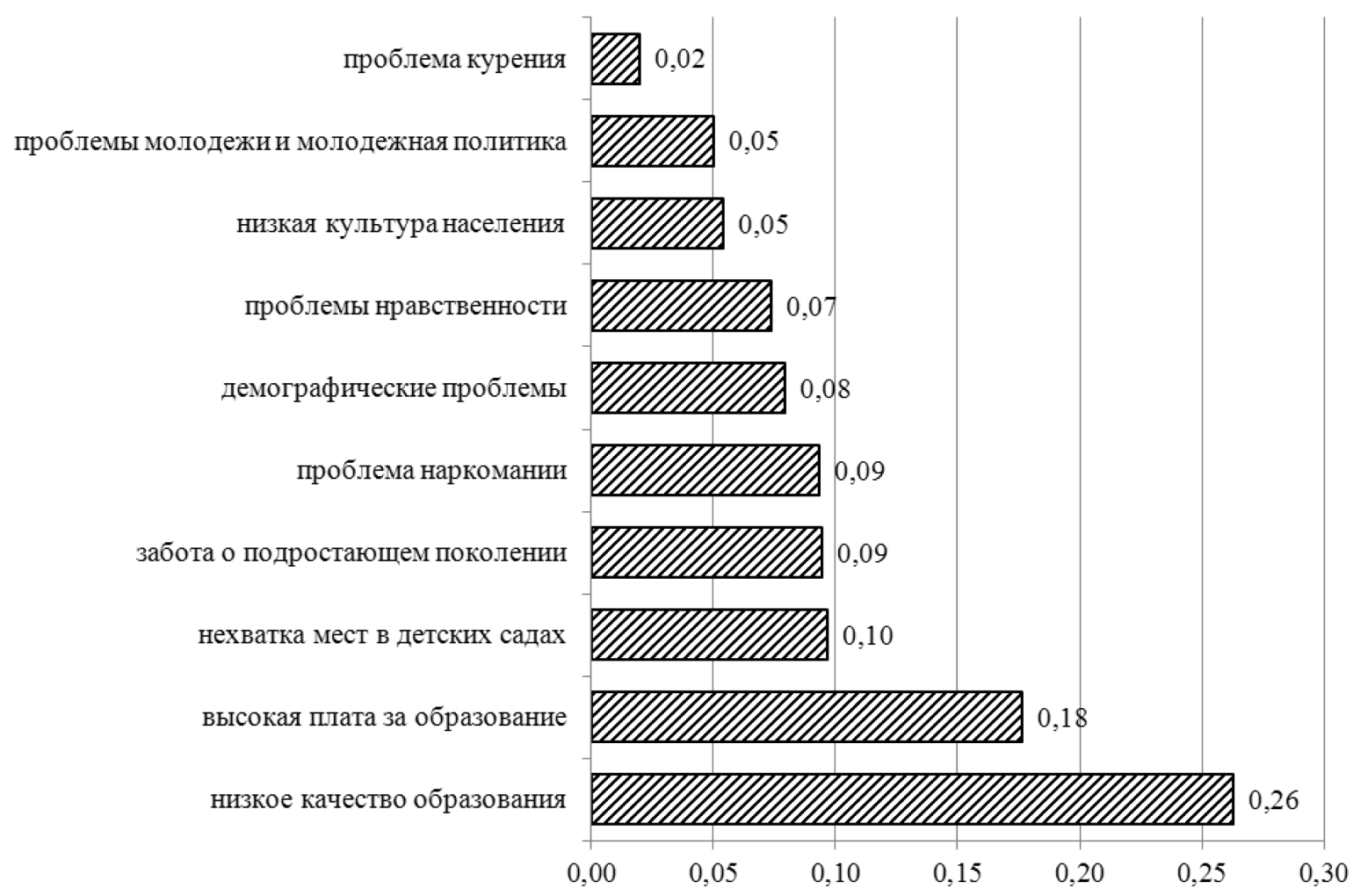

Рис. 4. Частотный ряд распределения групп ответов в классе «Забота о будущем поколении»

Произведенный нами анализ сгруппированных данных показал, что структура классов ответов по годам практически не отличается. Однако, для различных возрастных и социальных групп респондентов структура выделяемых проблем, отличается существенно. Для разделения ответов по проблемам, волнующим людей, используются данные по социально-демографическому портрету, которые собираются в ходе опросов.

\section{Оценка социального самочувствия населения Приморского края}

В последние годы в научных теориях, концепциях и социальных программах для оценки восприятия социально-экономической ситуации различными социальными группами и общностями стал использовать термин «социальное самочувствие».

Социальное самочувствие - эмоциональный аспект оценки представителями социальной группы своего общественного положения, уровня удовлетворения социально囚экономических и духовных потребностей, интересов. В социальном самочувствии выражается обобщенная оценка общественных настроений группы: экономических, политических, идеологических, национальных и др [2].

В рамках исследования социального самочувствия населения Приморского края 
было проведено два анкетных опроса в октябре 2014 года и в октябре 2015 года. В опросе участвовало около 500 респондентов в 2014 году и около 400 респондентов в 2015 году, представляющих различные слои населения края.

В соответствии с концепцией оценки социального самочувствия респондентам предлагалось дать собственные оценки уровня разрешения социально-экономических проблем в регионе по сравнению желаемым уровнем или с некоторым идеальным уровнем решения проблем (в процентах). В качестве списка проблем был предложен список проблем, выявленных в результате анализа данных предыдущих опросов. В качестве справочной информации к анкете прилагалась таблица с развернутой расшифровкой проблем (табл. 1). Кроме текущего состояния респондентам предлагалось дать свой прогноз по возможности решения перечисленных проблем через 5 и 10 лет.

Расчет средних оценок разрешения социально-экономических проблем в настоящее время и прогнозы их решения в будущем, по мнению населения, представлен на рис. 5.

Социальная напряженность и бедность

Низкое качество жизни

Несовершенное законодательство

Низкая заработная плата

Нестабильность экономической ситуации

Коррупция и преступность в органах власти

Низкая социальная защищенность

Неудовлетваренность работой властных стр

Низкое качество товаров и услуг

Преступность и личная безопасность

Ценовая политика

Экологические проблемы и природоохрана

Международная обстановка

Трудоустройство и занятость

Забота о будущем поколении

Инфраструктура и благоустройство

Доступность отдыха и развлечений

$$
0,0
$$
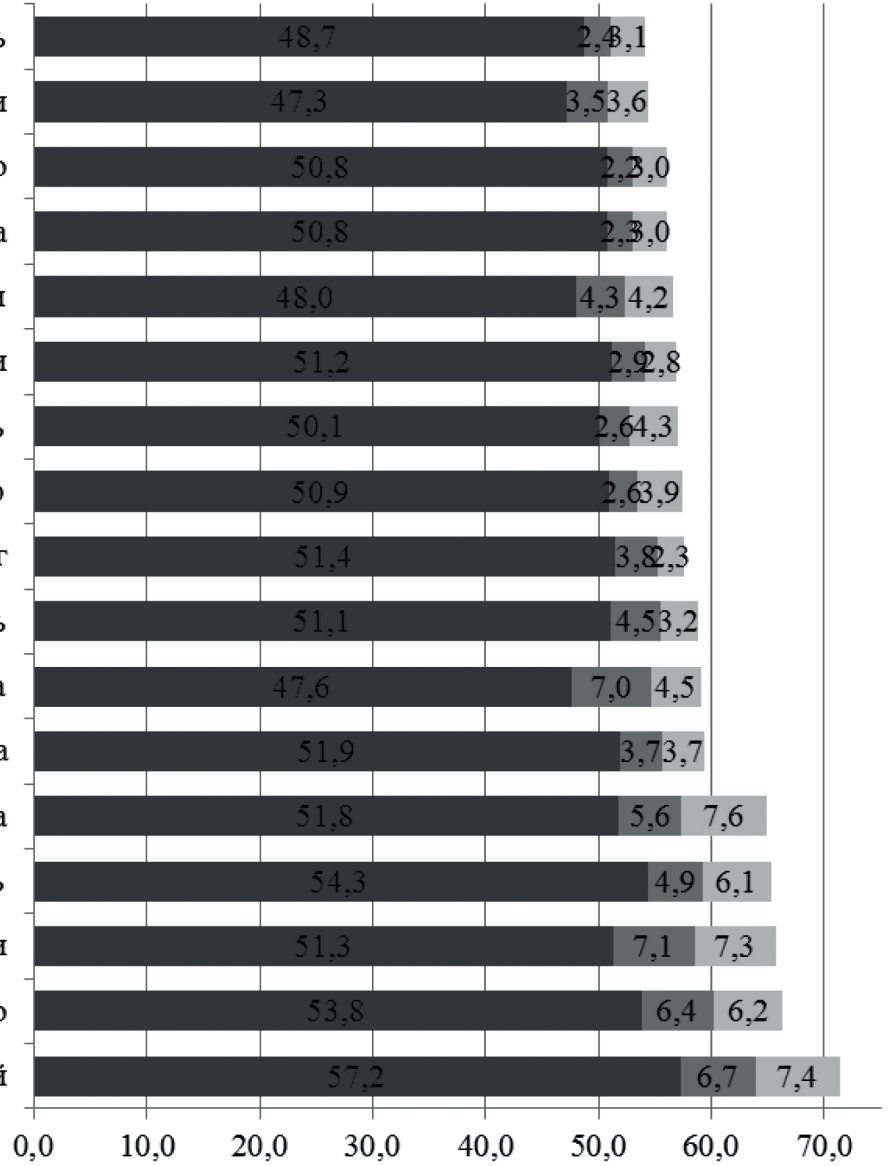

Рис. 5. Средние оценки степени решения основных социально-экономических проблем региона и прогнозы их решения через 5 и10 лет 
Средние оценки степени решения проблем лежат вблизи 50\%. То есть, большинство населения считает, что обстановка в крае неблагополучная. Прогнозы на будущее тоже не очень оптимистичны. Улучшение уровня решения проблем за пять и десять лет население оценивает в среднем на 4\% и 4,5\%. Такие оценки перспектив развития региона нельзя назвать оптимистичными. Здесь, конечно, необходимо учитывать, что последние опросы проводились на фоне продолжающегося в стране экономического кризиса. В настоящее время даже правительство страны не может с уверенностью утверждать, что самый сложный период кризиса пройден.

\section{Заключение}

Производство новых знаний в рамках когнитивного подхода требует разработки компьютерных технологий представления, хранения, обработки, интерпретации новых знаний.

Отмечая широкие возможности зарубежных компьютерных инструментальных средств анализа качественных данных, нельзя не отметить, что они не нашли своего распространения не только у отечественных ученых, занимающихся проблемами управления, но и у отечественных социологов. Эти средства имеют несколько другую направленность и больше предназначены для решения гуманитарных и лингвистических задач. Кроме того, такие средства малодоступны российским ученым и сложны в использовании.

В данной работе разработана методология анализа качественных данных, которые собираются с целью исследования социально-экономических процессов. Методология включает достаточно простые в применении компьютерные программные инструменты, которые могут быть использованы в рамках компьютерной среды EXCEL, которая является наиболее распространенной среди отечественных исследователей рынков. Методология с успехом использовалась при исследовании потребительских рынков, в частности рынка туристских услуг [12].

Достоинством компьютерной технологии является наличие интеллектуальной системы, которая может накапливать опыт исследователя. В настоящее время база знаний включает информацию по десяткам открытых вопросов. Знания, накопленные в процессе обработки открытых вопросов одним исследователем, легко можно передать другим исследователям в виде файла, что может существенно облегчить их работу.

\section{Библиография :}

1. Бялецкая Е.М., Квятковская И.Ю. 0 принципах когнитивного моделирования сложных систем // Вестник Астраханского государственного технического университета. - 2006. - № 1. - С. 116-119.

2. Гарькина И.А., Данилов А.М., Королев Е.В. Когнитивное моделирование сложных слабоструктурированных систем: пример реализации // Региональная архитектура и строительство - 2008. - № 2. - С. 16-21. 
3. Горелова Г.В. 0 когнитивном моделировании сложных систем, инструментарий исследования // Известия ЮФу. Технические науки. - 2012. - № 6 (131). - С. 236-240.

4. Авдеева 3.К., Коврига С.В., Макаренко Д.И. Когнитивное моделирование для решения задач управления слабоструктурированными системами (ситуациями) // Управление большими системами: сборник трудов. - 2007. - № 16. - С. 26-39.

5. Татарова Г.Г. Основы типологического анализа в социологических исследованиях: Учебное пособие / Г. Г. Татарова. - М: Издательский дом «Новый учебник», 2004. - 206 с.

6. Толстова Ю. Н. Масленников Е. В. Качественная и количественная стратегии. Эмпирическое исследование как измерение в широком смысле//Социологические исследования. 2000. № 10. С. 101 — 109.

7. Fielding N. G. G., Lee N. F. R. M., Lee R. M. Computer analysis and qualitative research. - Sage, 1998.

8. Готлиб, А.С. Введение в социологическое исследование. Качественный и количественный подходы. Методология. Исследовательские практики: учебное пособие - М: Флинта: МПСИ, 2005. - 384 с.

9. Загоруйко Н.Г.Прикладные методы анализа данных и знаний - Новосибирск:Изд-во Института математики, 1999. $-270 \mathrm{c}$.

10. Мартышенко С.Н., Мартышенко Н.С., Кустов Д.А. Инструментальные средства обработки анкетных данных в EXCEL // Информационные технологии моделирования и управления. - 2007. - №1. - С. 112-120.

11. Мартышенко С.Н., Мартышенко Н.С., Кустов Д.А. Цензурирование при обработке анкетных данных // Известия высших учебных заведений. Поволжский регион. - 2006. - №6(27). - С. 170-177.

12. Мартышенко С.Н., Мартышенко Н.С., Власенко А.А. Разработка стратегий развития туристской отрасли региона на основе изучения мнений потребителей // Экономический вестник Ростовского государственного университета. - 2007. - том 5 - №3. С. 219 - 227.

13. Мартышенко Н.С., Гусев Е.Г. Мониторинг индикаторов социального самочувствия жителей Приморского края в условиях экономического кризиса // Политика и Общество. - 2015. - 11. - С. 1517 - 1529. D0I: 10.7256/18128696.2015.11.17010.

14. Шульц В.Л., Кульба В.В., Шелков А.Б., Чернов И.В. Управление региональной безопасностью: анализ эффективности мониторинга социальной стабильности // Тренды и управление. - 2015. - 3. - С. 199 - 216. DOI: 10.7256/2307-9118.2015.3.16048.

15. Погодина И.В., Фраймович Д.Ю., Мищенко 3.В. Позиционирование параметров безопасности региональной социально-экономической системы в условиях модернизации // Вопросы безопасности. - 2012. - 1. - С. 55 - 80. URL: http://www.e-notabene.ru/nb/article_77.html

16. Гончарова Н.П., Ноянзина О.Е., Авдеева Г.С. Миграционные процессы и социальная безопасность рынка труда приграничных регионов России // Национальная безопасность / nota bene. - 2014. - 1. - C. 50 - 60. D0I: $10.7256 / 2073-8560.2014 .1 .9873$.

17. Л.В. Максимов Что такое мораль: проблема определения // Философия и культура. - 2012. - 10. - С. 115 - 126.

\section{References:}

1. Byaletskaya E.M., Kvyatkovskaya I.Yu. 0 printsipakh kognitivnogo modelirovaniya slozhnykh sistem // Vestnik Astrakhanskogo gosudarstvennogo tekhnicheskogo universiteta. - 2006. - № 1. - S. 116-119. 
2. Gar'kina I.A., Danilov A.M., Korolev E.V. Kognitivnoe modelirovanie slozhnykh slabostrukturirovannykh sistem: primer realizatsii // Regional'naya arkhitektura i stroitel'stvo. - 2008. - № 2. - S. 16-21.

3. Gorelova G.V. 0 kognitivnom modelirovanii slozhnykh sistem, instrumentarii issledovaniya // Izvestiya YuFU. Tekhnicheskie nauki. - 2012. - № 6 (131). - S. 236-240.

4. Avdeeva Z.K., Kovriga S.V., Makarenko D.I. Kognitivnoe modelirovanie dlya resheniya zadach upravleniya slabostrukturirovannymi sistemami (situatsiyami) // Upravlenie bol'shimi sistemami: sbornik trudov. - 2007. № 16. - S. 26-39.

5. Tatarova G.G. Osnovy tipologicheskogo analiza v sotsiologicheskikh issledovaniyakh: Uchebnoe posobie / G. G. Tatarova. - M: Izdatel'skii dom «Novyi uchebnik», 2004. - 206 s.

6. Tolstova Yu. N. Maslennikov E. V. Kachestvennaya i kolichestvennaya strategii. Empiricheskoe issledovanie kak izmerenie v shirokom smysle//Sotsiologicheskie issledovaniya. 2000. № 10. S. 101 -109.

7. Fielding N. G. G., Lee N. F. R. M., Lee R. M. Computer analysis and qualitative research. - Sage, 1998.

8. Gotlib, A.S. Vvedenie v sotsiologicheskoe issledovanie. Kachestvennyi i kolichestvennyi podkhody. Metodologiya. Issledovatel'skie praktiki: uchebnoe posobie - M: Flinta: MPSI, 2005. - 384 s.

9. Zagoruiko N.G. Prikladnye metody analiza dannykh i znanii - Novosibirsk: Izd-vo Instituta matematiki, 1999. - 270 s.

10. Martyshenko S.N., Martyshenko N.S., Kustov D.A. Instrumental'nye sredstva obrabotki anketnykh dannykh v EXCEL // Informatsionnye tekhnologii modelirovaniya i upravleniya. - 2007. - №1. - S. 112-120.

11. Martyshenko S.N., Martyshenko N.S., Kustov D.A. Tsenzurirovanie pri obrabotke anketnykh dannykh // Izvestiya vysshikh uchebnykh zavedenii. Povolzhskii region. - 2006. - №6(27). - S. 170-177.

12. Martyshenko S.N., Martyshenko N.S., Vlasenko A.A. Razrabotka strategii razvitiya turistskoi otrasli regiona na osnove izucheniya mnenii potrebitelei // Ekonomicheskii vestnik Rostovskogo gosudarstvennogo universiteta. 2007. - tom 5 - №3. S. 219 - 227.

13. Martyshenko N.S., Gusev E.G. Monitoring indikatorov sotsial'nogo samochuvstviya zhitelei Primorskogo kraya v usloviyakh ekonomicheskogo krizisa // Politika i Obshchestvo. - 2015. - 11. - C. 1517 - 1529. D0l: 10.7256/18128696.2015.11.17010.

14. Shul'ts V.L., Kul'ba V.V., Shelkov A.B., Chernov I.V. Upravlenie regional'noi bezopasnost'yu: analiz effektivnosti monitoringa sotsial'noi stabil'nosti // Trendy i upravlenie. - 2015. - 3. - C. 199 - 216. D0I: 10.7256/23079118.2015.3.16048.

15. Pogodina I.V., Fraimovich D.Yu., Mishchenko Z.V. Pozitsionirovanie parametrov bezopasnosti regional'noi sotsial'no-ekonomicheskoi sistemy v usloviyakh modernizatsii // Voprosy bezopasnosti. - 2012. - 1. - C. 55 - 80. URL: http://www.e-notabene.ru/nb/article_77.html

16. Goncharova N.P., Noyanzina 0.E., Avdeeva G.S. Migratsionnye protsessy i sotsial'naya bezopasnost' rynka truda prigranichnykh regionov Rossii // Natsional'naya bezopasnost' / nota bene. - 2014. - 1. - C. 50 - 60. DOI: 10.7256/2073-8560.2014.1.9873.

17. L.V. Maksimov Chto takoe moral': problema opredeleniya // Filosofiya i kul'tura. - 2012. - 10. - C. 115 - 126. 